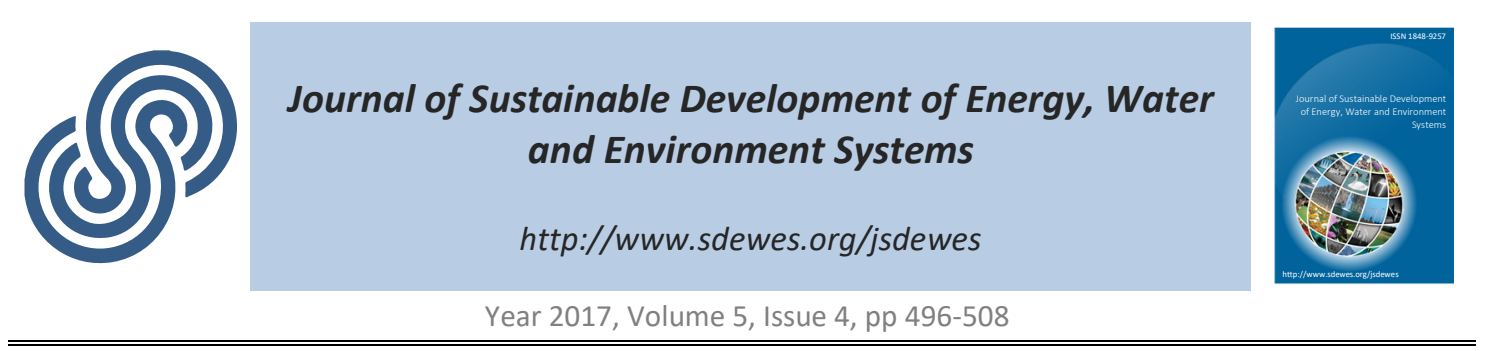

\title{
Building Regulations Related to Energy and Water in Indian Hill Towns
}

\author{
Ashwani Kumar \\ Department of Architecture and Planning, Malaviya National Institute of Technology Jaipur, Jaipur, \\ Rajasthan 302017, India \\ e-mail: ashwani.patiyal@gmail.com
}

Cite as: Kumar, A., Building Regulations Related to Energy and Water in Indian Hill Towns, J. sustain. dev. energy water environ. syst., 5(4), pp 496-508, 2017, DOI: http://dx.doi.org/10.13044/j.sdewes.d5.0161

\begin{abstract}
Energy and water are the two major concerns which humanity is presently facing at large, and many concerns are being expressed at the international, national and local level related to these critical issues. Optimizing the use of energy and water in buildings are significant challenges faced by architects and designers in developing countries like India while planning of townships and designing of buildings and their surrounding environments. Different building regulations are formulated in various Indian cities to optimize the use of energy and water in built environment. But, these regulations are not efficiently enforced and followed. As a result, the problem related to insufficient supply and inappropriate use of energy and water persists, which leads to excessive pressure on already scarce energy and water resources. Environmentally sensitive in hill towns of India are facing most of the issues, where provision and improvement of infrastructural facilities is a tedious task and may lead to enormous impacts on the environment. In this paper, an attempt is made to understand their issues and problems of different building regulations related to energy and water enforced in Indian hill towns. Valuable lessons are outlined related to formulation and implementation of building relations imposed on development in hilly areas in other countries. This paper also includes various interventions required to incorporate regulations related to energy and water in existing building regulations of Indian hill towns.
\end{abstract}

\section{KEYWORDS}

Energy, Water, Building regulations, Hill towns.

\section{INTRODUCTION}

Indian cities and towns are growing exponentially to meet ever increasing demand for buildings (residential, workplaces, recreational, institution) arising from the significant increase in urban population due to high growth rate and migration. Providing appropriate infrastructural facilities (for water and energy) in an urban settlement are the most challenging tasks due limited resources and high installation cost, operational and maintenance cost, high demand due to the large increase in urban population [1]. Indian cities, especially environmentally sensitive hill towns are facing many problems related to quality and quantity of water [2]. These problems include poor quality and impurities, reduction in ground and surface water sources, pollution and contamination of water source, low ground water recharge, and high runoff, high losses in water supply lines, inadequate quantity of municipal water, and low water conservation and reuse [3]. 
Similarly, there are crucial issues related to energy faced by Indian cities, which includes dependence on non-renewable energy sources, pollution, huge gap between demand and supply, use of high energy consuming device and instruments, non-adoption of renewable sources of energy, and lower concerns for energy conservation and optimal utilization. Many of the above-stated problems and issues related to energy and water in urban settlements can be resolved by implementing appropriate building regulations related to energy and water.

Energy and water being major environmental concerns for urban settlements, still, there are very few regulations enforced on built environment to address these crucial issues [4]. Moreover, due to the absence of regulations related to these, the building owners and architects do not give sufficient importance to these critical issues. The resultant development will have no or minimal provisions to mitigate the needs of energy and water. Buildings/settlements are entirely dependent on the external source and result in inappropriate and unsustainable development.

These problems/issues of building regulations are most critical in environmentally sensitive hill towns of north India, which require immediate attention for change/amendment in existing development pattern and development regulations.

\section{Hill towns in India}

Any area having altitude more than $600 \mathrm{~m}$ from mean sea level or an average slope of $30^{\circ}$ may be classified as hilly in India [5], which includes the Himalayas, the Central Highlands, the Deccan Plateau and the north-eastern hill ranges. Depending upon the altitude and prevailing climatic conditions, hill regions have been classified into three categories as Foot-hill regions (below 1,200 m), Mid-hill regions (1,200-3,500 m) and High-hill regions (above 3,500 m) [6]. Most of the hill regions (especially larger hill towns/stations) are declared as ecologically sensitive zones by the ministry of environment and forest, and any large scale development is prohibited in these environmentally sensitive areas [7]. These different hill regions have varied geo-environmental conditions and resources available for development. Moreover, development in hilly areas is further constrained by difficult terrain, steep gradients, complex geological structure, climate, and flora.

Most of the hill towns/stations like Shimla, Nainital, Dalhousie, Mussoorie, etc. are situated in the mid hill regions [8]. These hill towns have been experiencing great pressure for development (due to high population growth, massive tourist influx, and better living conditions) from last three decades, which has changed the environment and visual appearance of hill towns [9]. Hill towns have grown many a time more than their design and carrying capacity (Figure 1) and are under a lot of pressure for providing residential, educational, health, work, recreational facilities and supporting infrastructure. These are furthermore pronounced due to the scarcity of buildable land, as well as high property prices [10]. Due to rapid and irregular development, the risk of various natural disasters like earthquake, landslides, slope failure, flash floods, etc. and manmade disaster like accidents, fire, etc. has been increased tremendously in hill towns [11]. Furthermore, deforestation, an increase in the number of vehicles, non-scientific waste disposal has resulted in air and water contamination, which severely affecting the health of the residents [8].

Unlike most of the ecologically sensitive zones/areas of the world, Indian hill towns are the specific examples of massive urban development in environmentally sensitive areas (Figure 1), which are growing exponentially over and above of their carrying capacities and hampering/affecting the environment [4]. In most of the countries for development in hill regions and ecologically sensitive areas, separate regulations that focus on minimal and contextually appropriate development, without harming the environment and ecology of the area are formulated and legislated. 
Regulations enforced in major hill towns like Shimla, Manali, Dalhousie, Mussoorie, Nainital, Shillong, Srinagar and Gangtok are studied to understand various problems and issues of existing regulations related to energy and water, and attempts are made to have an in-depth understanding of these issues.
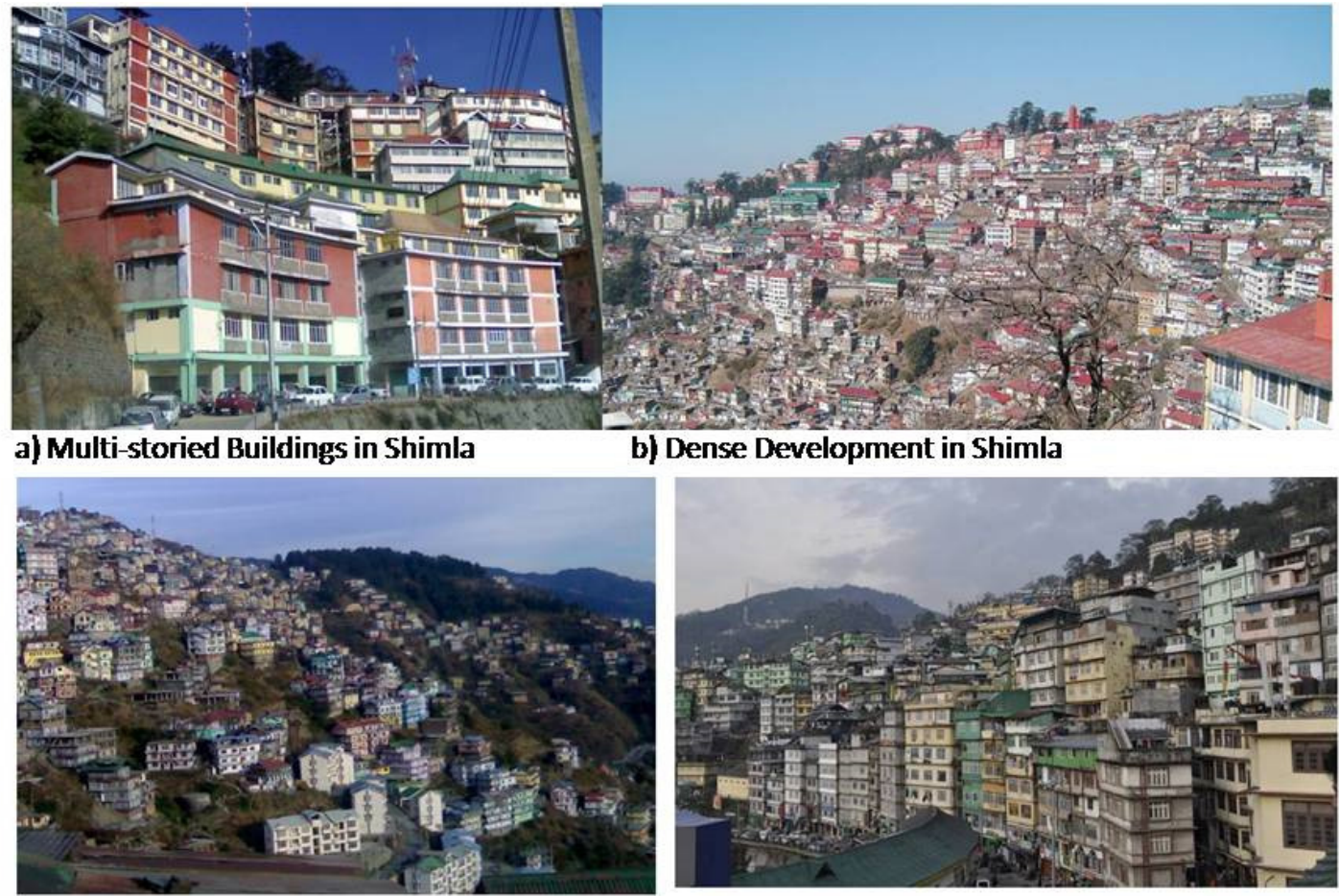

b) Dense Development in Shimla

c) Buildings encroaching on green areas in Shimla d) Dense multi-storied Development in Gangtok

Figure 1. Dense multi-storied development in hill towns

\section{MATERIALS AND METHODS}

Most of the part of this research work was performed through secondary data. However, some primary data have also been obtained for the same. Personal observation, discussion, survey, etc. methods were adapted to obtained observation and conclusion as well. The prevailing building regulations are collected from the secondary data available with different local governing authorities and relevant information is deducted from the regulations after review of the prevalent regulations. The building regulations prevalent in foreign countries like Bhutan and United States are collected from the relevant information available in various local authorities' websites.

\section{RESULTS AND DISCUSSIONS}

The various regulations related to energy and water prevailing in hill towns is discussed to highlight the various issues and problems. The best practices followed in two countries namely, Bhutan and United States are discussed in detail. Bhutan is consider as a case, as it has similar geo-environmental context like most of the Indian hill towns. The regulations prevailing in hill side development are also considered as they mostly leads to environmental protection and sustainable development in ecologically sensitive zones. Further general interventions which can be adopted for building regulations related to energy and water are discussed in this section.

\section{Regulations related to energy and water in hill towns}

Regulations related to, passive solar design, use of solar devices, protection of solar exposure/solar rights of buildings, formulation of setbacks as per solar exposure 
requirement, rainwater harvesting, drainage of the site, maintenance of drainage pattern, ground water recharge and reuse of water are studied in different hill towns. The prevailing building regulations related to these essential aspects enforced in various hill towns are considered and compared to highlight various problems and shortcomings in existing building regulations, as shown in Table 1.

Table 1. Building regulations related to energy and water in hill towns

\begin{tabular}{|c|c|c|c|c|c|c|c|c|}
\hline $\begin{array}{l}\text { Regulations } \\
\text { related to: }\end{array}$ & Shimla & Dalhousie & Manali & Mussoorie & Nainital & Srinagar & Shillong & $\begin{array}{l}\text { No. of towns } \\
\text { having } \\
\text { regulations }\end{array}$ \\
\hline $\begin{array}{c}\text { Solar passive } \\
\text { design }\end{array}$ & * & o & $\mathrm{O}$ & $\mathrm{O}$ & $\mathrm{O}$ & $\mathrm{O}$ & $\mathrm{O}$ & 1 \\
\hline $\begin{array}{c}\text { Energy efficient } \\
\text { devices }\end{array}$ & * & o & o & o & o & o & $\mathrm{o}$ & 1 \\
\hline $\begin{array}{l}\text { Protection of solar } \\
\text { rights of other } \\
\text { buildings }\end{array}$ & o & $\mathrm{o}$ & o & $\mathrm{o}$ & o & $\mathrm{o}$ & $\mathrm{o}$ & 0 \\
\hline $\begin{array}{c}\text { Setbacks in } \\
\text { accordance with } \\
\text { solar exposure }\end{array}$ & o & $\mathrm{o}$ & $\mathrm{o}$ & $\mathrm{O}$ & o & $\mathrm{o}$ & $\mathrm{o}$ & 0 \\
\hline $\begin{array}{l}\text { Rain water } \\
\text { harvesting }\end{array}$ & * & * & * & * & o & * & $*$ & 6 \\
\hline Drainage of site & $*$ & * & * & * & $*$ & $*$ & $*$ & 7 \\
\hline $\begin{array}{l}\text { Maintenance of } \\
\text { drainage pattern }\end{array}$ & * & * & * & * & * & * & * & 7 \\
\hline $\begin{array}{l}\text { Ground water } \\
\text { recharge regulation }\end{array}$ & * & * & * & $*$ & o & * & $*$ & 6 \\
\hline $\begin{array}{l}\text { Regulation for } \\
\text { reuse of waste } \\
\text { water }\end{array}$ & $*$ & $\mathrm{o}$ & $\mathrm{o}$ & $\mathrm{O}$ & o & $\mathrm{o}$ & $*$ & 2 \\
\hline
\end{tabular}

Presently, energy being one of the most important issues for development, as there are concerns at the international, national and regional level related to its conservation and optimal use. Shimla is the only Indian hill town that has incorporated regulations related to passive solar design and energy efficient fixture, to minimize energy consumption for maintaining comfort conditions in public, government, and semi-government buildings. No other Indian hill town has such regulations related to passive solar design in buildings. But, in spite of rules enforced in Shimla, these regulations related to the use of passive solar features are not followed in most of the buildings, as there are no provisions to check and ensure their compliance and also, no incentive is given to the owner's to incorporate energy efficient design and features (Figure 2).

Regulations to protect the solar exposure of one building from the shadow of other building that leads to mutual shading of building in cold climatic zones and result in the increase in consumption of energy for maintaining comfort conditions inside the buildings are not found in any hill town. Similar, the different setback regulations in-forced in various hill towns of India are formulated without considering the need/necessity of solar exposure to buildings for a particular period throughout the year [12]. These inappropriate setbacks lead to poor natural light in buildings which results in increased use of artificial lighting for general lighting purposes even during the day time. Lack of natural light and ventilation in buildings will lead to dampness and the unhealthy living environment in buildings (Figure 3). These regulations are borrowed from Delhi Master Plan or National Building Code and are applied on development in hill towns 
without any or minimal modification, which leads to inappropriate development in hill towns.

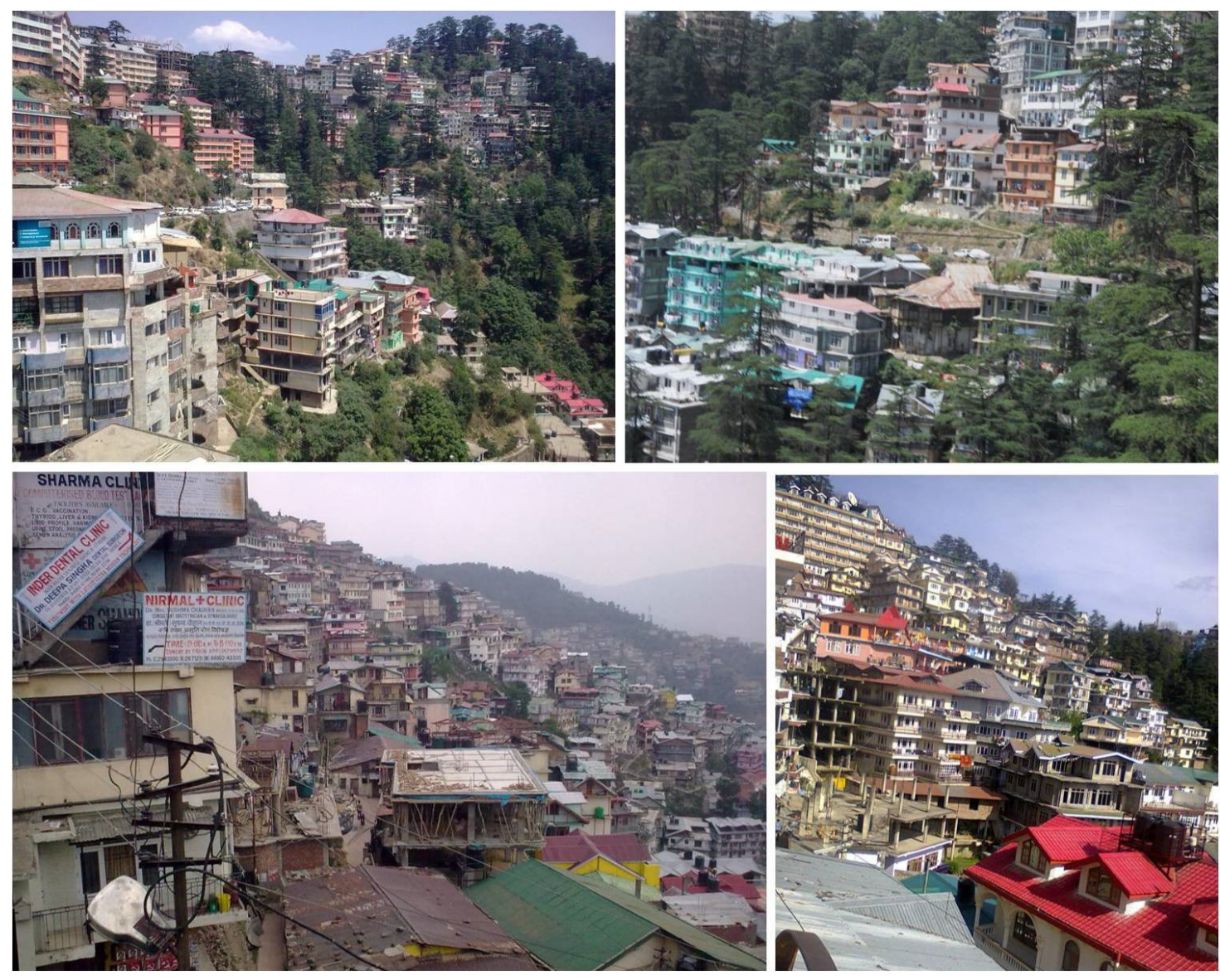

Figure 2. Excessive development in Shimla, much more than their carrying capacities

Every hill town has regulations enforced related to rainwater harvesting, drainage of site and maintenance of existing drainage pattern, signifies the importance of these essential regulations for environmental protection in hill towns. Regulations related to rainwater harvesting exist in most of the hill towns, but Rainwater Harvesting Systems (RWHS) are not implemented in the majority of buildings constructed [13]. There are issues related to the detailing of the RWHS regulations, as in many hill towns these are specified as a single sentence irrespective of the type of the building/use, the size, shape, and topography of the plot. These regulations do not provide information about the appropriate type of RWHS for a particular plot and the utilization of rainwater collected.

Hill towns like Mussoorie, Nainital, and Manali have regulations enforced related to preservation of natural water sources. In spite of that, natural water sources like streams, waterfalls, rivers, lakes, etc. present in or around hill towns are facing serious problems related to pollution and siltation due to improper waste management, encroachment, and prevalent inappropriate site development and construction practices [4].

Every hill town studied has regulations related to maintenance of upstream drainage pattern, ground water recharge and site drainage reflecting the importance of maintaining drainage pattern. But, in spite of these regulations natural drainage pattern has changed in hill towns due to human interventions like encroachments, buildings built across drainage course.

There are no incentives regarding deduction in developmental charges, subsidy to purchase energy and water efficient equipment and provision of extra Floor Area Ratio (FAR) given to building owners for implementing regulations for environmental 
protection in hill towns, except in the case of Shillong. The incentive in terms of $10 \%$ reduction in developmental approval fee is given for providing setback as 1.5 times the prescribed setback in Shillong. Also, there is a decrease in development fee by $10 \%$ for providing provisions for rainwater harvesting system and reuse of waste water.
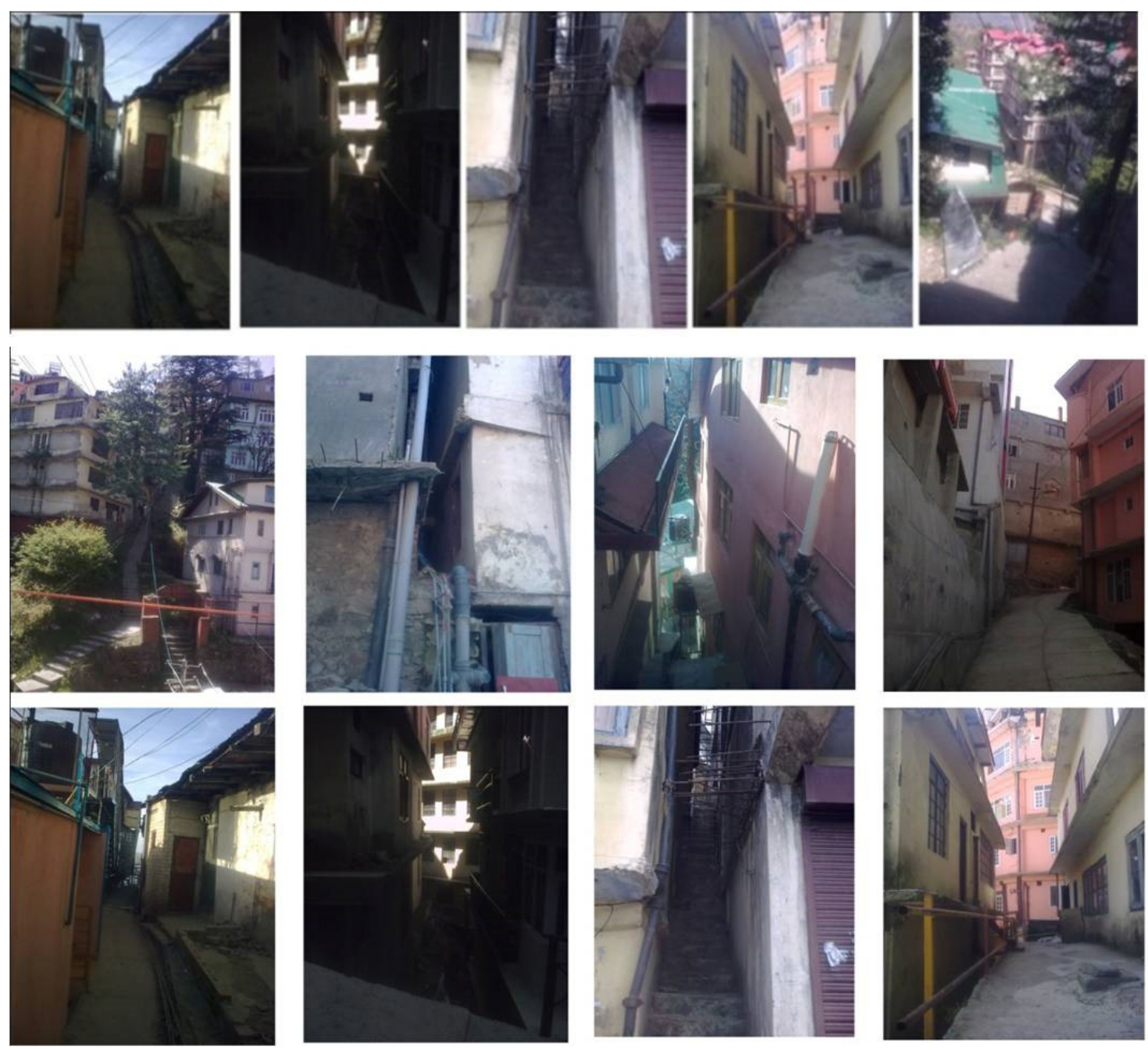

Figure 3. Inadequate solar exposure to buildings in Shimla

Various issues of building regulations are absence/unavailability of regulations related to some crucial aspects, the inappropriateness of existing building regulations and insufficient or inadequate enforcement of building regulations. As a consequence of these issues, there is pressure on energy and water sources to fulfill the ever-increasing demand. Problems like high consumption of energy for maintaining comfort conditions, depleting water sources, enormous pollution of surface and ground water source, high encroachment and deforestation in catchment areas, conversion of permeable grounds into hard impermeable surface result in deterioration of the environmental quality, which adversity affect the health and well-being of residents.

\section{Regulations related to energy and water as practiced in Bhutan and United States}

Regulations enforced in the United States (for hillside development) and Bhutan is studied to understand prevalent practices for water and energy regulations in different hill regions. Bhutan is a country located in the Himalayas and has similar geo-environmental characteristics as most of the hill towns of India located in the Himalayan region. Moreover, Bhutan has not compromised the environmental quality and biological 
diversity for development and economic progress [14]. Bhutan has sound environmental regulatory framework consists of many policies and acts, associated regulations, guidelines, codes of practice and environmental standards and has been institutionalized within Government agencies [15]. The United States, being a developed country has state of the art regulations and enforcement mechanism for protection of the sensitive environment in Hillside areas from adverse impacts of new development and to regulate the construction of new buildings.

As per Hillside Development Regulations in the United States, criteria adopted for site selection and placement of buildings are accessibility, geological stability, maintenance of natural appearance for hillsides and ridgelines, minimal grading, view protection and minimizes visual and environmental impact [16]. Moreover, in some hill towns, part of plots is required to be kept undisturbed and this undisturbed part of site increases with the increase in slope gradient. E.g. in the case of White County, Georgia, the percentage of plot area which should remain undisturbed is specified according to the average slope of the plot under consideration for development. This area to be remain undisturbed varies from $40 \%$ for plots having the slope gradient $24 \%$ or less to $90 \%$ for the plots having slope gradient $40 \%$ or more. Likewise, the maximum percentage of impervious surface on a lot is also specified and with the increase in the average slope in a plot, the percentage of impervious surface is decreasing. For example, the maximum percentage of lot that may be impervious surface is $30 \%$ for plots having the slope less than $24 \%$. However, the maximum percentage of lot that may be impervious surface is reduced to $10 \%$ for sites/plots having the slope between 35 to $39 \%$, as shown in Table 2 [17].

Table 2. Regulations related to ground coverage and percent of lot not to be disturbed

\begin{tabular}{cccc}
\hline $\begin{array}{c}\text { Average slope of } \\
\text { lot to be developed }\end{array}$ & $\begin{array}{c}\text { Minimum percent of } \\
\text { lot that must remain } \\
\text { undisturbed }\end{array}$ & $\begin{array}{c}\text { Maximum percent of } \\
\text { lot that may be disturbed }\end{array}$ & $\begin{array}{c}\text { Maximum percent } \\
\text { of lot that may be } \\
\text { impervious surface }\end{array}$ \\
\hline $24 \%$ or less & $40 \%$ & $60 \%$ & $30 \%$ \\
$25-29 \%$ & $50 \%$ & $50 \%$ & $25 \%$ \\
$30-34 \%$ & $60 \%$ & $40 \%$ & $20 \%$ \\
$35-39 \%$ & $80 \%$ & $20 \%$ & $10 \%$ \\
$40 \%$ or more & $90 \%$ & $10 \%$ & $5 \%$ \\
\hline
\end{tabular}

Source: Mountain and Hillside Protection Ordinance: White County, Georgia

In Thimphu city - the capital of Bhutan, no development or building construction shall be permitted within 30 meters of the edge of the watercourse/side of the gullies or banks of the rivers or streams. No development or building construction shall be permitted within 15 meters of the edge of all natural rivulets or gulleys and natural drainage channels [18]. Every site development should include channels at the lower elevation/level of the site which discharges rainwater runoff into public storm water drains. Moreover, rainwater harvesting regulations are implemented having an underground water collection cistern at the lower portion of the site to collect rainwater [19]. This collected rainwater water can be used for landscaping, car washing, and other non-potable uses.

Also, the setbacks are required for ensuring adequate solar exposure to buildings during winters and these needs to be formulated following the spacing required between two buildings to have solar exposure of specific hours on the shortest day of year, i.e. $22^{\text {nd }}$ December. This provision for the formulation of setbacks to have an adequate solar exposure is included in existing regulations (as an appendix) for the purpose of reference and revision in future. Also, it is specified that due to the inability of implementing authority to enforce these regulations related to solar exposure, existing setback rules are 
formulated without considering the space requirement to ensure sufficient solar exposure in winters.

As per San Francisco Planning Code, upper parts of a building adjoining a public sidewalk need to have vertical setback(s) to preserve the openness of the street to the sky and to avoid the perception of overwhelming mass, these upper setbacks depends on the height of the street wall. Moreover, it is essential to achieving as much sun as possible on public sidewalks having a high volume of pedestrian use [20].

A light plane of $45^{\circ}$ is drawn from the building to protect the solar exposure of the building constructed on opposite side of the road. The height of building and setbacks are decided accordingly so that a building does not cast its shadow on buildings present on the opposite side of the road.

\section{Intervention for regulations related to energy and water in hill towns}

Existing building regulations are not appropriate to cater all the prevalent challenges of the development in hill towns. Therefore, different interventions are required to formulate and implement regulations related to energy and water in hill towns of India. These interventions can be divided into various categories as interventions for:

- Formulation of regulations related to energy and water for new buildings;

- Formulation of regulations related to energy and water for existing buildings;

- Ensuring effective enforcement and compliance;

- Upgradation of technical expertise of professionals and authorities.

Interventions required for formulation of regulations related to energy and water for new buildings. The formulation of new and efficient regulation related to energy and water for new buildings in hill towns require the following types of interventions:

- Setting of performance standards for the different use: There is a need to set the desired performance standard for different use of buildings in hill towns. Various regulations related to energy and water for various use need to be focused on these desired standards;

- Formulations of regulations related to energy and water at area level: Different regulations need to be formulated and implemented at area/zone level depending upon the peculiar characteristics of vegetation, slope gradient, and direction, soil type, water table, proximity to different natural features, which can vary in different areas/zones of hill town. For this purpose, the city or town area is required to be classified into different zones based on the various intrinsic characteristics like topography slope direction, vegetation, soil type, water table, etc.;

- Regular monitoring and improvement in safety regulations: There is a need to have continuous studies and monitoring of existing development. Appropriate modifications/improvements to the current rules related to energy and water should be made based on the outcome of these studies. Moreover, impact assessments of these regulations need to be undertaken, and regulations need to be suitably modified depending on the results of these studies.

Interventions required for formulating regulations related to energy and water for existing buildings. Interventions required for formulation of regulations related to energy and water includes the following steps:

- Setting of performance standards for existing buildings: There is a need to set the desired performance level or standard for existing buildings. Based on the desired performance standard of regulations related to energy and water, existing building premises need to be retrofitted with features for energy and water conservation. Also, a suitable method of feasible retrofitting needs to be identified or suggested; 
- Regular monitoring and condition assessment of retrofitted structure: There is a need to have continuous monitoring and condition assessment of retrofitted buildings with energy and water conservation measures to ensure the efficient functioning.

Interventions for ensuring effective enforcement and compliance. To ensure adequate compliance with different regulations related to energy and water, the proposal submission process, developmental approval, site visits and completion certificate stages need to be modified to have various provisions to ensure effective adoption and compliance of regulations related to energy and water.

Interventions for upgradation of technical expertise of professionals and authorities. Short-term courses focused on explaining various aspects of building regulations, the appropriate mechanism for enforcement and compliance, and the likely impacts of non-compliance of building regulations need to be conducted to impart sufficient skills and technical knowledge to professional working. Similarly, knowledge needs to be given to professional of local development authorities, so the checking of the development proposal and construction at the site need to be inspected accurately and efficiently.

\section{Formulation of regulations related to energy and water}

Existing environmental regulations of hill towns are mostly need-based that are enforced to mitigate the harsh impacts of development and urbanizations on various components of the environment so that ecological balance should not be triggered off. For example, to control the depleting ground water table, regulations related to rainwater harvesting and ground water recharge are enforced. Along with these need-based or mandatory building regulations that should be compulsory to all development, there is a need to formulate 'impact based regulations' i.e., regulations based on the effects of a building on the environment and the surrounding areas.

The relevant quality standards need to be established to formulate different rules, which should also consider the resurgence of deteriorated environment quality in hill regions. From these environmental quality standards, different necessary and impact based regulations related to energy and water are required to be formulated. To ensure compliance with enforced regulations in an efficient and effective manner, these regulations need to be formulated as necessary regulations and impact based regulations, in the next sub-section.

Formulation of necessary regulations related to energy and water. For the formulation of necessary building regulations like energy efficient design, rainwater harvesting, site drainage, etc. various factors such as plot area, use, and building bulk need to be considered. Different provisions under every regulation need to be specified depending upon these factors (plot size, use and building bulk) so that the proposed necessary provisions for energy and water can be implemented:

- Regulations related to rainwater harvesting: Rainwater harvesting is necessary to maintain the water table and minimize loads/pressure on municipal water supply. It is mandatory to provide rainwater harvesting system for all new buildings designed and constructed in hill towns except row housing. The capacity of storage tank needs to be decided based on the rainfall data and roof/collector area. For detached houses and all other buildings (except plotted development) rainwater harvesting system to reuse collected rainwater for different purposes like gardening, floor washing, in water closets, etc. should be mandatory, and rainwater harvesting system to recharge groundwater is proposed to be 
constructed for row and semi-detached buildings (Table 3). Construction of rainwater harvesting tank should be allowed in building setbacks and should not be included in FAR. The completion certificate to the owner shall only be issued after the proper inspecting the installation and functioning of rainwater harvesting system in the plot/site;

Table 3. Proposed types of rain water harvesting system for different use in hill towns

\begin{tabular}{ccc}
\hline No. & Type of building & Type of rain water harvesting system \\
\hline 1 & Row building & Ground water recharge type RWHS \\
2 & Semi detached & Ground water recharge type RWHS \\
3 & Detached & Water reuse type \\
4 & Group housing and other uses such as & Water reuse type \\
\hline
\end{tabular}

- Regulations for the Protection of Natural Drainage Pattern: The natural drainage pattern is required to be maintained or kept unchanged while developing the site. It is the responsibility of the owner to collect upstream water, channelized it through the site and carefully dispose of the site under consideration. Moreover, it is the responsibility of the owner to maintain the drainage profile within site intact. While inspecting the building for the completion certificate, the maintenance of natural drainage pattern should also be checked, and if it is changed then, completion certificate should not be issued to the owner;

- Preservation of natural features and elements: No development should be allowed on sites having prominent natural features like ridges, lakes, springs, rivers, rivulet, and seasonal streams. A minimum distance of $5 \mathrm{~m}$ should be maintained from springs, rivulets, and seasonal streams, and a minimum distance of $10 \mathrm{~m}$ should be maintained from lakes, rivers to preserve different natural features present in hill towns;

- Regulations for incorporation of energy efficient design and feature: It should be mandatory for all group housing, office, government and semi-government buildings to incorporate various energy efficient features in different stages of selection, planning, design and operation/functioning.

Formulation of impact based regulations. Impact based regulations that are essential to improve the environmental quality in hill towns and to mitigate the adverse impacts of development on hill regions should be made. These should include regulations for plantation of trees, preservation of fertile top soil and its reuse, terrace gardens in place of lost green vegetation cover. These regulations should be formulated and implemented based on the impact of new development on the environment so that impacts of new development should be minimized in the environment of hill towns:

- Topsoil protection and erosion control: Top fertile soil needs to be conserved and reuse at other places for plantation purposes. It should not be dumped/filled with other soil lying below the top soil or non-fertile soil. Appropriate measures like vegetation plantation, soil stabilization, drainage channels and drainage correction are required to be taken so that the erosion of soil from the site should be prevented;

- Reuse of waste water after purification: In all buildings (except plotted residential development) the waste water obtained from basins, kitchen sinks, etc. should be treated, purified and reused for different purposes.

Along with formulation of building regulations for environmental protection in hill towns, there is a need to devise a new and efficient mechanism for the implementation of 
both mandatory and impact based regulations for environmental protection, so that these regulations should be implemented and followed effectively for environmental protection in hill towns.

\section{General recommendations for effective formulation and compliance of regulations}

The following recommendations are also suggested to ensure the effective formulation and necessary compliance of different regulations related to energy and water in hill towns:

- It is recommended that the performance criteria for the purpose of formulating regulations related to energy and water need to be developed judicially at areas level after conducting field studies. These regulations related to energy and water should have sufficient details to cover all aspects of their adoption and implementation for all types of use and plots;

- It is recommended that setback regulations are required to be formulated to have direct solar exposure for a specific duration for all buildings throughout the year. Topography and slope direction of the plot, the height of proposed building and width of access road need to be considered for deciding front setback in hill towns. Different setbacks (front, side and rear) need to be calculated separately for every hill town, as different hill towns have varied geographical locations, which leads to variation in incident solar radiations;

- It is recommended that local governing authorities should involve at various stages of development projects in an active/responsive manner to regulate and monitor developmental activity;

- Adoption of various provisions for energy and water conservation need to be ensured by local governing authorities while conducting site visits and issuing completion certificate in hill towns. As all hill towns have a fragile environment, the implementation of different provisions for environmental protection in hill towns is most crucial;

- There is a need for dissemination of information/knowledge related to building regulations to the residents. So that residents should know the building regulations and understand different provisions, which need to be fulfilled for effective compliance with building regulations for a particular use;

- Various incentives such as rebate in development fees, municipal taxes, infrastructural services charges as well as the subsidy for energy efficient fixtures and passive solar devices need to be made for buildings, which follow building regulations for environmental protection and aesthetics;

- There is a need to have regular monitoring of various building regulations for new and existing development to assess their current working condition so that these provisions should work efficiently. It is also recommended that reviews of existing provisions should be made on the regular basis so that improvements in various building regulations should be done.

\section{CONCLUSIONS}

Hill towns in India are the unique examples enormous and rapid urban development to meet the ever-increasing demand for urbanization on the ecologically fragile sloping terrain. These hill towns have critical issues related to energy and water such as poor quality, impurities and silt in water, pollution and reduction in ground and surface water sources, low ground water recharge, high runoff, reduction in ground water table, high losses in water supply lines; dependence on non-renewable energy sources, huge gap between demand and supply of water and energy, non-adoption of renewable sources of energy, and lower concerns for energy and water conservation and optimal utilization. 
Optimizing the use of energy and water in buildings are significant challenges faced by planners and architects while planning of townships and designing of buildings and their surrounding environments. Regulations related to passive solar design, use of solar devices, protection of solar exposure/solar rights of buildings, formulation of setbacks as per solar exposure requirement, rainwater harvesting, drainage of the site, maintenance of drainage pattern, ground water recharge, and reuse of water are crucial for appropriate development in hill towns. It is found from the study that, regulations related to some crucial aspects are not available in many hill towns. Moreover, if regulations are present, they are not appropriate for that particular context, and are improperly enforced and have poor compliance.

Best practices related building regulations in ecologically sensitive areas and sloping terrain are studied, and it is found from the study that, there is a reduction in intensity of development with an increase in slope gradient. Setbacks are formed by considering the solar exposure to buildings and protection of one building from the shadow of other. Also, there is a need to protect different natural features like rivers, upstream drainage pattern, slopes, natural vegetation, etc.

Various interventions are required to improve existing building regulations or formulate new building regulations related to crucial aspects and to ensure effective enforcement and compliance. These interventions can be grouped into four different categories as interventions required for formulations of regulations for new buildings, existing buildings, ensuring effective implementation and compliance, and upgradation of technical expertise of professional and authorities.

Furthermore, building regulations like, adoption of energy efficient design, adoption of rainwater harvesting, protection of natural drainage, preservation of natural feature, etc. are considered under mandatory regulations, and it is proposed that different provisions under these mandatory regulations should depend on factors like plot size, use and building bulk. Various rules like plantation of trees, preservation of fertile top soil and its reuse, terrace gardens in place of lost green vegetation cover are classified under impact based regulations and it is proposed that these regulations should be formulated and implemented based on the impact of new development on the environment. Some general recommendations are also proposed for suitable formulation and efficient enforcement and compliance of various regulations related to energy and water.

\section{REFERENCES}

1. Maitra, A. K., Development of Hill Capital: Shimla-2035, $52^{\text {nd }}$ National Town and Country Planning Conference on Development of Hill Capitals: Shimla Vision 2025, pp 9-15, Shimla, India, 2003.

2. Seam, A. K., General Factors for Planning a Hill Town, Journal of Indian Institute of Architects, pp 27-29, 1995.

3. Sekar, S. P. and Thirumeni, M., Planning Strategies for Hill Stations in Ecosensitive Zones, Spatio-economic Development Record, Vol. 9, pp 35-37, 2002.

4. Kumar, A. and Pushplata, Building Regulations for Environmental Protection in Indian Hill Towns, International Journal of Sustainable Built Environment, Vol. 2, No. 2, pp 224-231, 2013, https://doi.org/10.1016/j.ijsbe.2014.04.003

5. Bureau of Indian Standards, National Building Code 2005, Bureau of Indian Standards, New Delhi, India, 2005.

6. Pushplata and Kumar, A., Building Regulations: As a Means of Ensuring Sustainable Development in Hill Towns, Journal of Environmental Research and Development, Vol. 7A, No. 1A, pp 553-560, 2012.

7. Menon, M., Kapoor, M. and Kohli, K., India's notified Ecologically Sensitive Areas (ESAs): The Story so far..., Kalpavriksh, Delhi \& WWF-India, New Delhi, India, 2009. 
8. Kumar, A. and Pushplata, City Profile: Shimla, Cities Journal, Vol. 49, pp 149-158, 2015, https://doi.org/10.1016/j.cities.2015.08.006

9. Jutla, R. S., Visual Image of the City: Tourists' versus Residents' Perception of Simla, a Hill Station in Northern India, Tourism Geographies, Vol. 2, No. 4, pp 404-420, 2000, https://doi.org/10.1080/146166800750035512

10. Institute of Town Planners India, ITPI Newsletter, No. 1, 2004.

11. Karki, B., Urban Risk Reduction through Effective Disaster Management Plan A Case Study of Shimla City Himachal Pradesh, India, International Journal of Scientific \& Technology Research, Vol. 4, No. 2, pp 67-73, 2015.

12. Kumar, A. and Pushplata, Approach to Formulate Setback Regulations for Indian Hill Towns, International Journal of Sustainable Built Environment, Vol. 4, No. 1, pp 91-99, 2015, https://doi.org/10.1016/j.ijsbe.2015.03.001

13. TCPO Shimla, Cumulative Detail of Approved Government \& Private Buildings with Respect to Implementation of Rain Water Harvesting System for the Period 1999 to 09/2011 in all Planning/Special Areas, Shimla, India, 2011.

14. Asian Development Bank, Bhutan Country Environmental Analysis, 2004, http://www.adb.org/sites/default/files/institutional-document/32180/bhu-cea-nov200 4.pdf, [Accessed: 03-April-2016]

15. Royal Government of Bhutan, National Report Bhutan: In Pursuit of Sustainable Development, The United Nations Conference on Sustainable Development, 2012, https://sustainabledevelopment.un.org/content/documents/798bhutanreport.pdf, [Accessed: 03-April-2016]

16. Olshansky, R. B., Regulation of Hillside Development in the United States, Environmental Management, Vol. 22, No. 3, pp 383-392, 1998, https://doi.org/10.1007/s002679900113

17. Department of Community Affairs Quality Growth Grant Program, County of White, Georgia, Mountain and Hillside Protection Ordinance: White County, USA, 2004.

18. Department of Urban Development \& Housing, Royal Government of Bhutan, Bhutan Building Rules - 2002 (BBR-2002), Bhutan, 2002.

19. Department of Urban Development \& Housing, Royal Government of Bhutan, Development Control Regulations 2004 for Thimphu, Bhutan, 2004.

20. American Legal Publishing Corporation, San Francisco, California Planning Code, USA, 2011. 